\title{
Deposition and Characterization of Molybdenum Thin Film Using Direct Current Magnetron and Atomic Force Microscopy
}

\author{
Muhtade Mustafa Aqil,, ${ }^{1}$ Mohd Asyadi Azam, ${ }^{2}$ Mohd Faizal Aziz, ${ }^{3}$ and Rhonira Latif ${ }^{3}$ \\ ${ }^{1}$ Faculty of Electronics and Computer Engineering, Universiti Teknikal Malaysia Melaka, Hang Tuah Jaya, \\ 76100 Durian Tunggal, Melaka, Malaysia \\ ${ }^{2}$ Carbon Research Technology Research Group, Advanced Manufacturing Centre, Faculty of Manufacturing Engineering, \\ Universiti Teknikal Malaysia Melaka, Hang Tuah Jaya, 76100 Durian Tunggal, Melaka, Malaysia \\ ${ }^{3}$ Institutes of Microengineering and Nanoelectronics (IMEN), Universiti Kebangsaan Malaysia, 43600 Bangi, Selangor, Malaysia
}

Correspondence should be addressed to Mohd Asyadi Azam; asyadi@utem.edu.my

Received 9 June 2016; Accepted 29 December 2016; Published 31 January 2017

Academic Editor: María J. Lázaro

Copyright (C) 2017 Muhtade Mustafa Aqil et al. This is an open access article distributed under the Creative Commons Attribution License, which permits unrestricted use, distribution, and reproduction in any medium, provided the original work is properly cited.

In this paper, pure molybdenum (Mo) thin film has been deposited on blank Si substrate by DC magnetron sputtering technique. The deposition condition for all samples has not been changed except for the deposition time in order to study the influence of time on the thickness and surface morphology of molybdenum thin film. The surface profiler has been used to measure the surface thickness. Atomic force microscopy technique was employed to investigate the roughness and grain structure of Mo thin film. The thickness and grain of molybdenum thin film layer has been found to increase with respect to time, while the surface roughness decreases. The average roughness, root mean square roughness, surface skewness, and surface kurtosis parameters are used to analyze the surface morphology of Mo thin film. Smooth surface has been observed. From grain analysis, a uniform grain distribution along the surface has been found. The obtained results allowed us to decide the optimal time to deposit molybdenum thin film layer of 20-100 nm thickness and subsequently patterned as electrodes (source/drain) in carbon nanotube-channel transistor.

\section{Introduction}

In recent years, the researches in microelectromechanical systems (MEMS) have developed remarkably, following the advanced of nanotechnology. The development of lithographic processes enables the fabrication of a wide variety of material-based miniaturized devices [1-4]. These systems have a rising importance in the automotive industry, magnetic storage devices, and all of those applications where microsensors or microactuators are necessary. Thus, it is crucial to face the newly emerged problems related to the reduce dimensionality. MEMS are 10-100 times smaller than macromachines; therefore surface forces often exceed the volume forces and problems associated with friction/adhesion; wear and surface contamination become relevant. In this context, tribological studies have a key role in the optimization of these components $[5,6]$.

Thin films and coatings play a critical role in everything from food containers to photovoltaic [7-9]. To meet such varied needs, they are made from every class of material and by numerous processes including physical and chemical vapor deposition techniques, atomic layer deposition, and sol gel processing [10]. A key step in developing any new film is characterizing its surface structure and physical properties, whether in engineering commercial products [11] or pursuing fundamental materials science studies [12].

Molybdenum (Mo) is a promising material to be used as electrodes (source/drain) in microelectronics. Mo thin film possesses interesting properties such as high electrical conductivity [13] and good chemical stability. Molybdenum is 
TABLE 1: Input parameters for sputtering.

\begin{tabular}{lc}
\hline Input parameter & Range \\
\hline DC power & 200 Watt \\
Working pressure & 10 mTorr \\
Argon flow & $20 \mathrm{sccm}$ \\
Deposition time & $5-85$ minutes \\
\hline
\end{tabular}

commonly used as electrodes because of its ohmic contact to silicon [14]. Therefore, molybdenum thin film characterization towards microelectronic utilization is very important for some applications such as in carbon nanotube transistor and resonant gate transistor $[15,16]$. The sputtering deposition technique is widely used among the researchers to fabricate thin film due to its advantages such as creating thin films with smaller grain size, many grain orientation, and better adhesion with the substrate [17]. Smaller grains impede the dislocation motion and improve toughness as well.

Recently, many researches have been done on the deposition of molybdenum thin films, electrical and morphological studies of Mo thin film for solar cell, and mechanical and tribological studies of molybdenum nitride thin films [13, 1822]. Nevertheless, no study has been carried out on electrodes (source/drain) fabrication which needs specific thickness and grain structure in nanodevices, for example, in the growth of carbon nanotube as channel between the electrodes (source/drain).

In this work, molybdenum thin film is deposited and characterized in order to be used as electrodes for carbon nanotube transistor. Thin film molybdenum layer has been deposited on a silicon wafer. DC magnetron sputtering which is a method of physical vapor deposition technique for thin film is used; it is considered to be one of the most commonly used techniques [23]. In this study, the influence of deposition time on thickness, grain, and roughness of Mo thin film layer has been carried out while argon flow rate, DC power, and working pressure have been made constant during deposition. One of scanning probe microscopy (SPM) mode which is atomic force microscopy (AFM) technique is used to characterize the samples $[24,25]$. Surface roughness and grain analysis of the samples are analyzed by Image AnalysesP9 (IA-P9) while the thickness is measured with a surface profiler.

\section{Material and Methods}

2.1. Sputtering Process (Film Deposition). In DC magnetron sputtering process, pure molybdenum round target $(99.95 \%)$ with 5 inch diameter and 0.25 inch thickness has been used to deposit Mo on blank $\left(1 \times 1\right.$ inch $\left.^{2}\right)$ Si substrate. The substrates have not been subjected to any heating treatment before the sputtering process. Table 1 shows the input parameters for the sputtering process.

There are 5 samples of Mo thin film layer deposited at different sputtering time from 5 minutes to 85 minutes. Specific Mo thickness for carbon nanotube transistor's electrode can be achieved by varying the sputtering time.
2.2. Morphological Characteristic Using AFM. For our samples, morphology and surface texture have been studied using AFM technique. AFM as an excellent device is one of the most common techniques which are widely used in thin film characterization. Knowing the surface topography at nanometric resolution allows researchers to investigate dynamic biological process [26], tribological properties [27], mechanical manufacturing [28], and mainly thin film surfaces [29].

Researchers use AFM technique because it allows evaluation and precise observation of thin film characteristics. Furthermore, AFM can operate in ambient condition and does not need any special sample preparation [30]. The most commonly used parameters to study surface texture include roughness, waviness, flows, and lay. All of these parameters represent random deviation of the surface. After we obtained $2 \mathrm{D}$ and $3 \mathrm{D}$ images by AFM technique in noncontact mode, the resulting images were analyzed in AP-9 software.

2.3. Surface Roughness Analysis. The most common parameters measured for roughness were the roughness average $\left(R_{\mathrm{a}}\right)$ and the root mean square $\left(R_{\mathrm{q}}\right)$, sometime called RMS. $R_{\mathrm{a}}$ is the arithmetic average value of the deviation of the trace above and below the mean value $\mu$ (center line). In other words, $R_{\mathrm{a}}$ is a vertical deviation which is the mean heights variation of the surface area according to the reference plan [31]. RMS roughness $\left(R_{\mathrm{q}}\right)$ measures the root mean square deviation of a profile and is used in calculating the skew and kurtosis parameter. $R_{\mathrm{q}}$ values found for all sample were higher than $R_{\mathrm{a}}$. The mathematical explanation of $R_{\mathrm{a}}$ and $R_{\mathrm{q}}$ is given by the following equations:

$$
R_{\mathrm{a}}=\frac{1}{N x * N y} \sum_{j=1}^{N y} \sum_{i=1}^{N x}\left|Z_{i j}-\mu\right|,
$$

where $N x * N y$ is data sample size in the array $Z i j$ which is the source discrete function in the $X Y$ plane and $\mu$ is the mean value the first momentum of the distribution given by

$$
\begin{aligned}
\mu & =\frac{1}{N x * N y} \sum_{j=1}^{N y} \sum_{i=1}^{N x} Z_{i j} \\
R_{\mathrm{q}} & =\sqrt{\frac{1}{N x * N y} \sum_{j=1}^{N y} \sum_{i=1}^{N x}(Z i j-\mu)^{2}} .
\end{aligned}
$$

Surface skewness $\left(R_{\text {sk }}\right)$ characterizes the symmetry of distribution. It is nonzero for symmetric distributions, positive for distributions with dominating right tail, and negative for distributions with dominating left tail. If the value of $R_{\mathrm{sk}}$ is positive, peaks become dominant in the distribution and if it is negative, valleys become dominant in the distribution [32]. Surface skewness is given by

$$
R_{\mathrm{sk}}=\frac{1}{N x * N y R_{\mathrm{q}}^{3}} \sum_{j=1}^{N y} \sum_{i=1}^{N x}(Z i j-\mu)^{3} .
$$

Coefficient of kurtosis $\left(R_{\mathrm{ka}}\right)$ is a measurement of spikiness distribution profile, above and below the reference plan. The 
TABLE 2: Thickness and the average thickness for Mo thin film with different deposition time.

\begin{tabular}{|c|c|c|c|c|c|c|}
\hline Unit & & & $\mathrm{nm}$ & & & $\mathrm{nm} / \mathrm{s}$ \\
\hline Deposition time $(\min )$ & Test 1 & Test 2 & Test 3 & Test 4 & Average & Deposition rate \\
\hline 5 & 9.27 & 10.9 & 12.4 & 7.89 & 10.115 & 0.0337 \\
\hline 20 & 269.96 & 266.75 & 268.28 & 267.44 & 268.1075 & 0.2234 \\
\hline 35 & 498.76 & 491.67 & 472.11 & 489.06 & 485.65 & 0.2312 \\
\hline 65 & 876.18 & 878.90 & 872.44 & 876.45 & 875.9925 & 0.2246 \\
\hline 85 & 1114.40 & 1116.37 & 1079.44 & 1137.29 & 1111.875 & 0.2180 \\
\hline
\end{tabular}

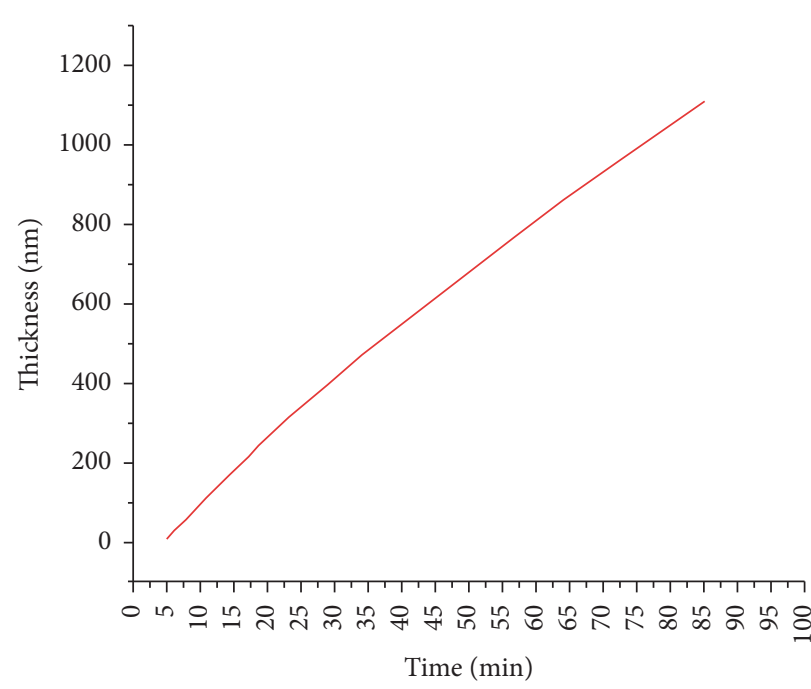

(a)

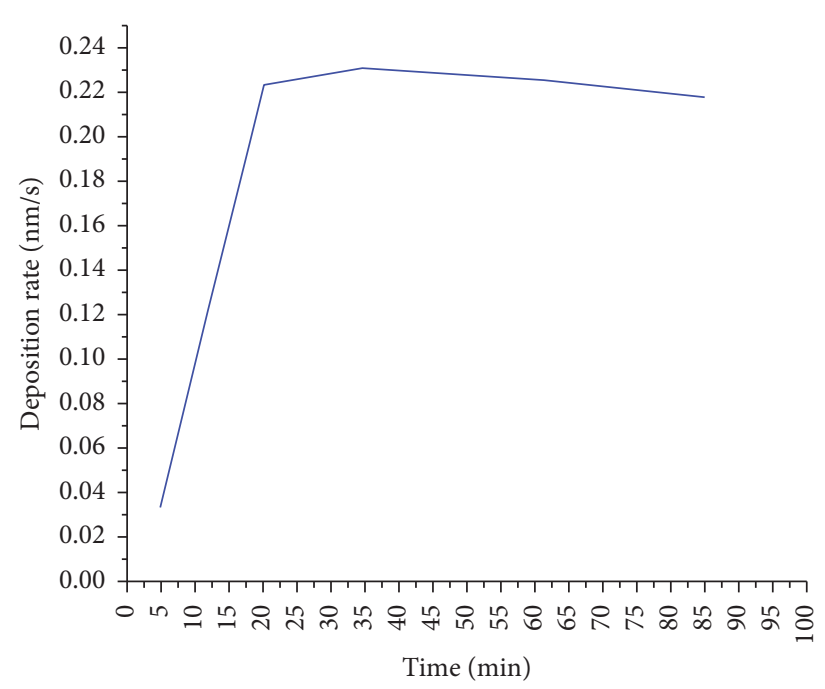

(b)

Figure 1: Trend between (a) thickness and (b) deposition rate with respect to time.

surface is considered Gaussian if $R_{\mathrm{ka}}=3$, spiky if $R_{\mathrm{ka}}>3$, or bumpy for $R_{\mathrm{ka}}<3$ [32]. The following formula presents $R_{\mathrm{ka}}$ :

$$
R_{\mathrm{ka}}=\frac{1}{N x * N y R_{\mathrm{q}}^{4}} \sum_{j=1}^{N y} \sum_{i=1}^{N x}(Z i j-\mu)^{4}-3 .
$$

Skewness and kurtosis parameter are important in giving better understanding of the surface. Skewness parameter indicates whether the peak distribution is symmetrical while kurtosis parameter determines whether the distribution of height (histogram) is Gaussian.

\section{Results and Discussion}

3.1. Thin Film Thickness. The measurement accuracy of thin film thickness is very important for many applications like semiconductor devices, displays, and thin film for optical product coatings. Average thickness can be determined by knowing the average step height (ASH) at any location in the scan area using surface profiler dektak150. Four measurements have been done in every sample at different places. Table 2 shows the thickness measurement and deposition rate. Figures 1(a) and 1(b) present the trends between time and thickness and the trend between time and deposition rate, respectively. In Figure 1(a), the thickness of Mo thin film layer increases linearly with respect to time. The result in Figure 1(b) shows that the deposition rate at the beginning of deposition process is small and starts to increase with time to the point that it became constant. The deposition rate has been measured to be constant for all samples deposited for more than 20 minutes.

3.2. Surface Roughness. Like thickness, surface roughness analysis is important to thin film due to its contribution in both mechanical and electrical transport properties. Conducting thin film roughness has a tangible impact on device performance [33]. 2D and 3D AFM images for Mo film are shown in Figure 2 for time deposition at 5 minutes to 85 minutes.

In Figure 3, the histogram and peak distribution are presented. Histogram is the heights distribution and it possesses a bell shape. Peak is the accumulated heights distribution. In order to clearly explain Figure 3, we should understand the statistical value parameter and amplitude which help to clarify the histogram shape and peak distribution. It is necessary to know the amplitudes for $R_{\mathrm{a}}$ and $R_{\mathrm{q}}$ calculated by (1) and (2), respectively. High $R_{\mathrm{a}}$ means rough surface; small $R_{\mathrm{a}}$ means smooth surface. Smooth surface is usually more resistive than rough surface against friction and wear. Our samples have low roughness as shown in Table 3. According to [34], the height distribution of most surfaces may approach a Gaussian distribution if $R_{\mathrm{q}} / R_{\mathrm{a}}$ value is up 

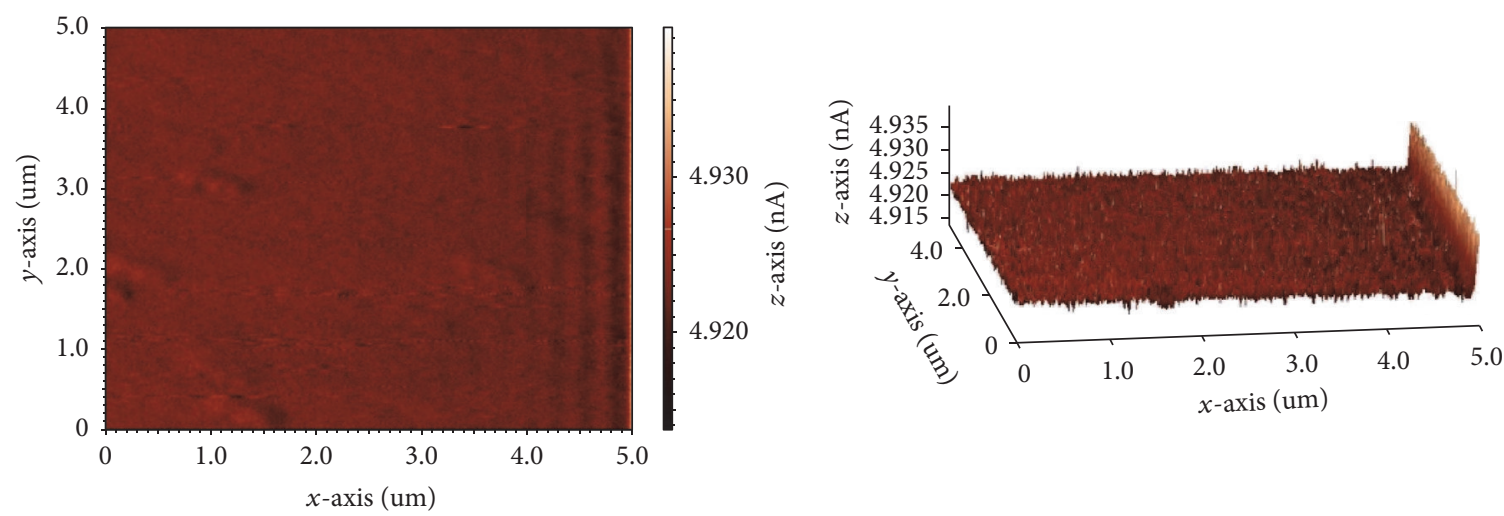

(a)
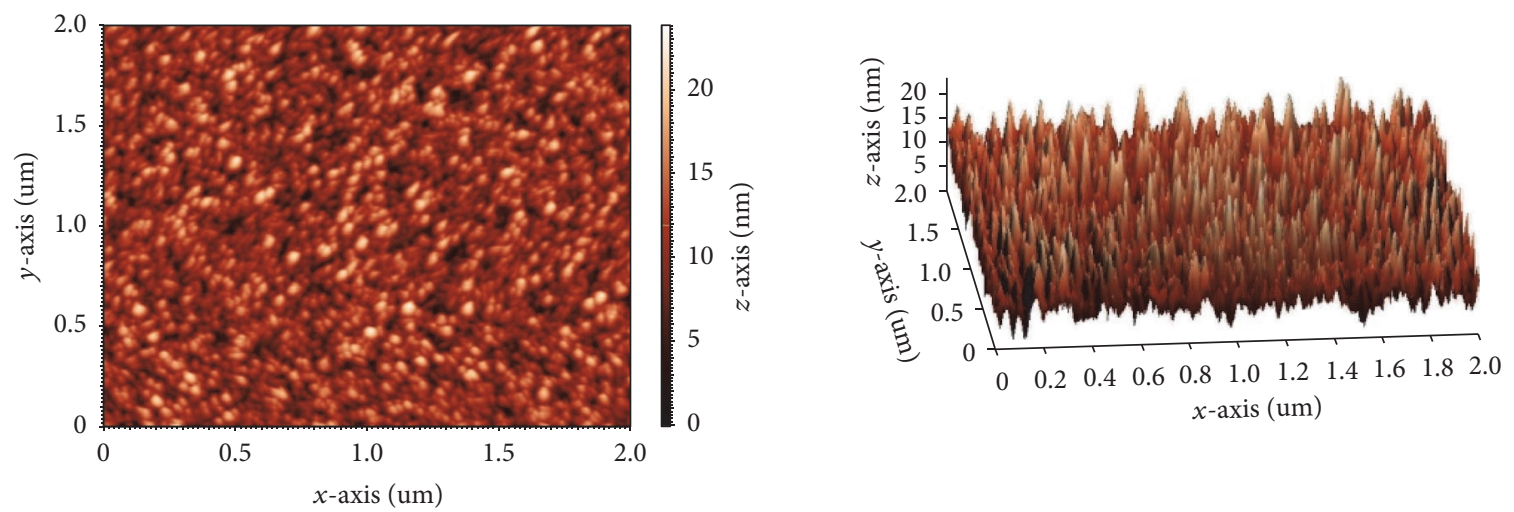

(b)
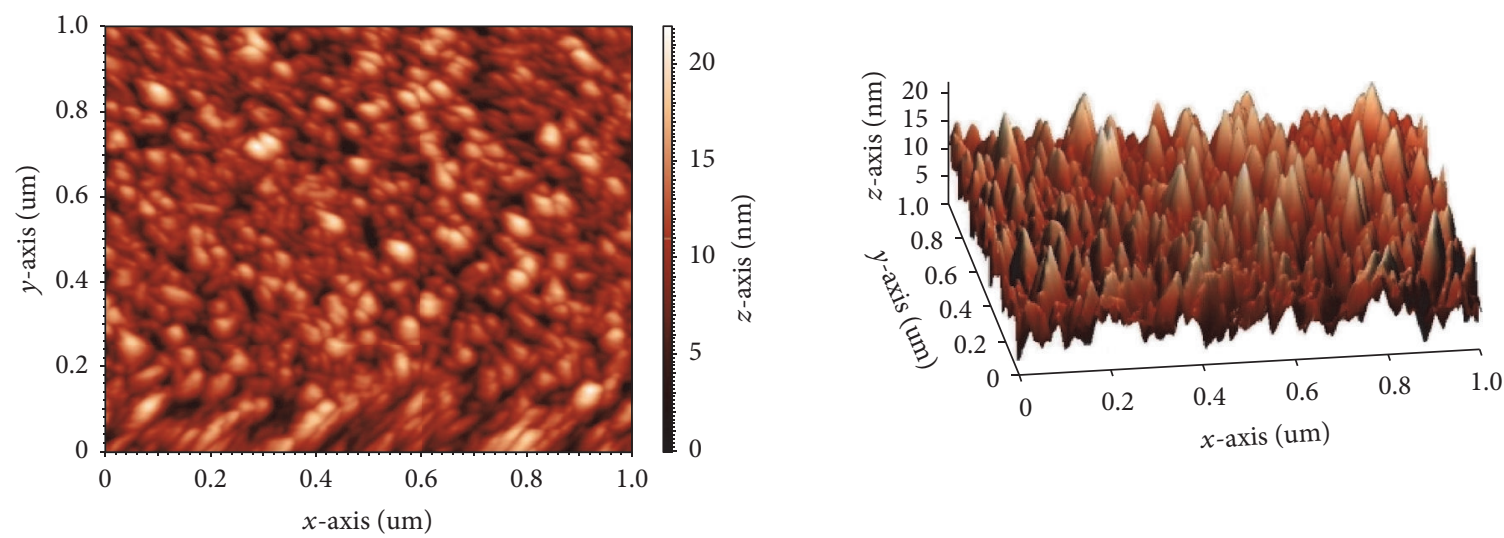

(c)
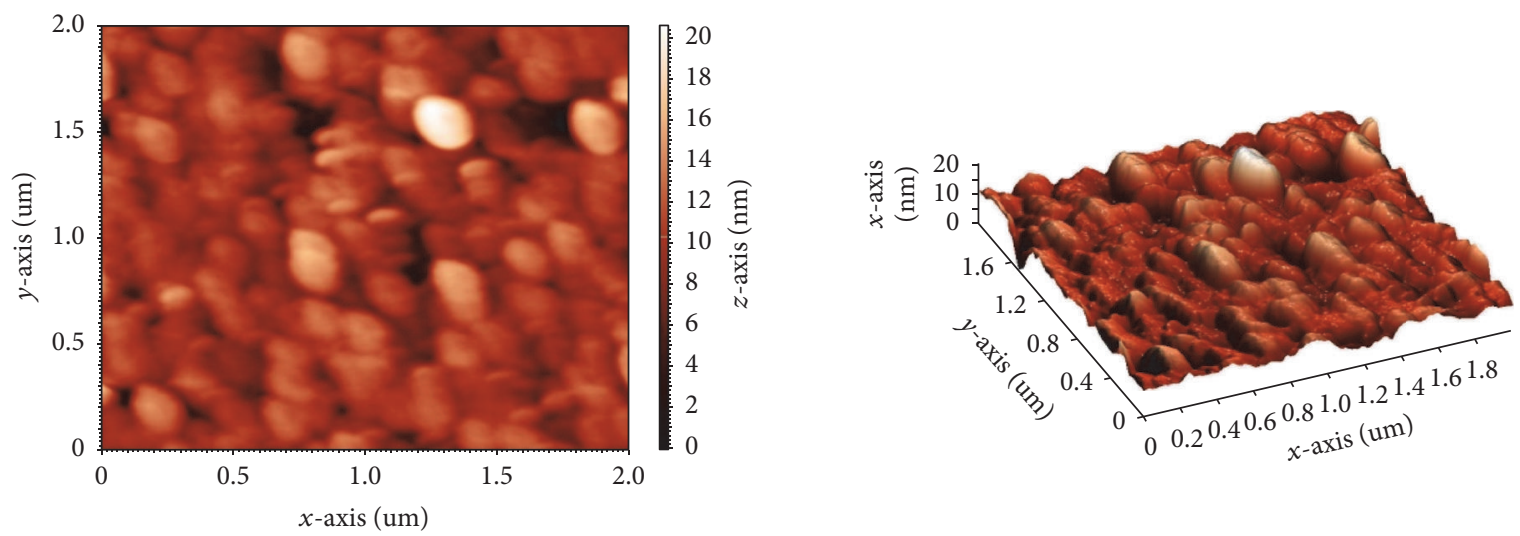

(d)

FIgure 2: Continued. 


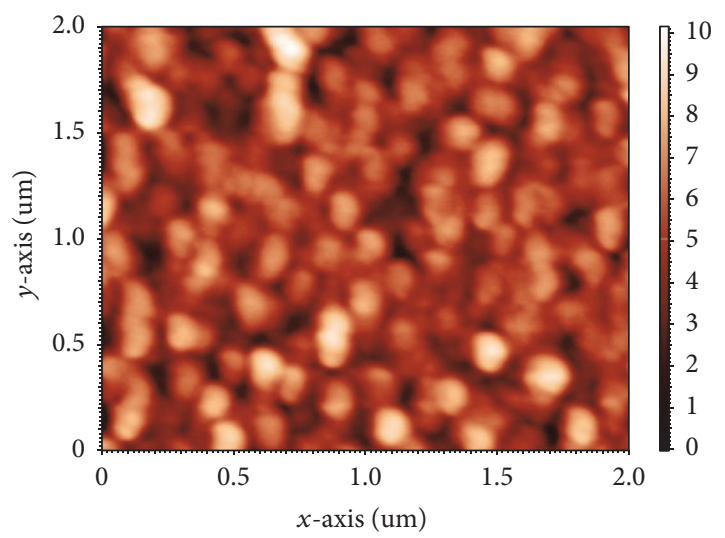

$$
\text { ¿્త }
$$

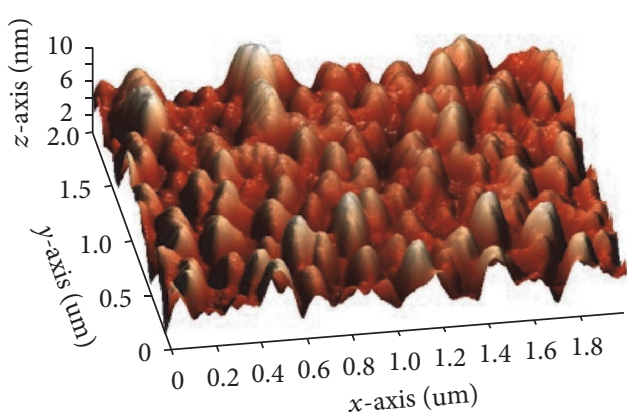

(e)

Figure 2: 2D and 3D AFM image samples with different deposition time, (a) $5 \mathrm{~min}$, (b) $20 \mathrm{~min}$, (c) $35 \mathrm{~min}$, (d) $65 \mathrm{~min}$, and (e) $85 \mathrm{~min}$.

TABLE 3: Roughness parameter of Mo thin film according to different deposition time.

\begin{tabular}{lccccc}
\hline Unit & \multicolumn{2}{c}{$\mathrm{nm}$} & $R_{\mathrm{q}} / R_{\mathrm{a}}$ & $R_{\mathrm{sk}}$ & $R_{\mathrm{ka}}$ \\
Deposition time (min) & $R_{\mathrm{a}}$ & $R_{\mathrm{q}}$ & & & \\
\hline 5 & 1.33 & 1.69 & 1.27 & 0.22 & 3.7 \\
20 & 2.58 & 3.23 & 1.25 & 0.35 & 2.97 \\
35 & 2.44 & 3.06 & 1.25 & 0.33 & 3.04 \\
65 & 1.57 & 1.99 & 1.26 & 0.21 & 4.7 \\
85 & 1.17 & 1.46 & 1.25 & 0.22 & 2.9 \\
\hline
\end{tabular}

to 1.31. The calculated values for $R_{\mathrm{q}} / R_{\mathrm{a}}$ in our experiment for all samples are approximately equal to 1.25 which means that for all 5 samples, the height distributions tend to be Gaussian. Referring to skewness and kurtosis definition in Section 3.2, these parameters describe the height symmetry. In our experiment, the values for skewness for all samples, which has been calculated using (4), are positive in a range of $0.21-0.35$. Thus, the peak distribution in Figure 3 shows that the right tail is longer than left tail. In addition, the hills are dominant over the valleys which indicate that the distributions are not perfectly symmetric. Values for Kurtosis as calculated in (5) are greater than 3 for samples with deposition time of 5 minutes, 35 minutes, and 65 minutes which indicate that the surface is spiky and the distribution is leptokurtic [23]. However, the surface is bumpy and the distribution is platykurtic [23] for samples with 20-minute and 85-minute deposition time, related to kurtosis value of less than 3.

The results clearly show that the roughness of molybdenum thin films decreases with respect to time. Furthermore, the films surfaces have waviness surface texture. For all samples, the histogram distributions are Gaussian and the peak distributions are dominant over the valleys.

3.3. Grain Analysis. Grain analysis method visualizes the section of the grain ensemble taken at a predefined relative level common for all grains. It collects basic geometric
TABLE 4: Grain analysis of Mo thin film according to deposition time.

\begin{tabular}{|c|c|c|c|c|}
\hline \multirow{3}{*}{$\begin{array}{l}\text { Unit } \\
\text { Deposition } \\
\text { time (min) }\end{array}$} & \multicolumn{4}{|c|}{ Average } \\
\hline & $\mu \mathrm{m}^{2}$ & & $\mu \mathrm{m}$ & \\
\hline & Area & Size & Perimeter & Length \\
\hline 5 & 0.0035 & 0.046 & 0.19 & 0.068 \\
\hline 20 & 0.017 & 0.12 & 0.48 & 0.175 \\
\hline 35 & 0.0011 & 0.03 & 0.12 & 0.04 \\
\hline 65 & 0.0023 & 0.04 & 0.175 & 0.058 \\
\hline 85 & 0.003 & 0.045 & 0.2 & 0.065 \\
\hline
\end{tabular}

characteristics of particles in the ensemble, including section area, volume, average size, local height, maximum height, maximum size, average height, and perimeter. A particular geometric characteristic for a section of grain ensembles are collected and presented in a histogram. Grain analysis method analyzes AFM images of granular ensembles on the surface under few assumptions, including that the particles of the ensemble are located on a base surface, the shape of the particles is sufficiently convex, and the particles are separated.

In previous images for Mo samples, IA-P9 image processing software analyzed and generated quantitative information for both individual and group of grains. In a group of particles, a statistical measurement can be gathered. Furthermore, counts of particles and distribution of all particle sizes, surface area, and volume are the most common statistic measurement. For individual grain, physical properties such as surface texture, morphology, and $3 \mathrm{D}$ size information (height, length, and width) can be measured using the same software. In Figure 4, 2D images show grain distribution for Mo thin film with different deposition time. The images show very good distribution of grain on all over the sample area. Figure 5 illustrates histogram plots of quantitative analysis for Mo thin films with different deposition time. The images show a very good grain distribution all over the area. Table 4 concludes the average of all measured parameters (grain 

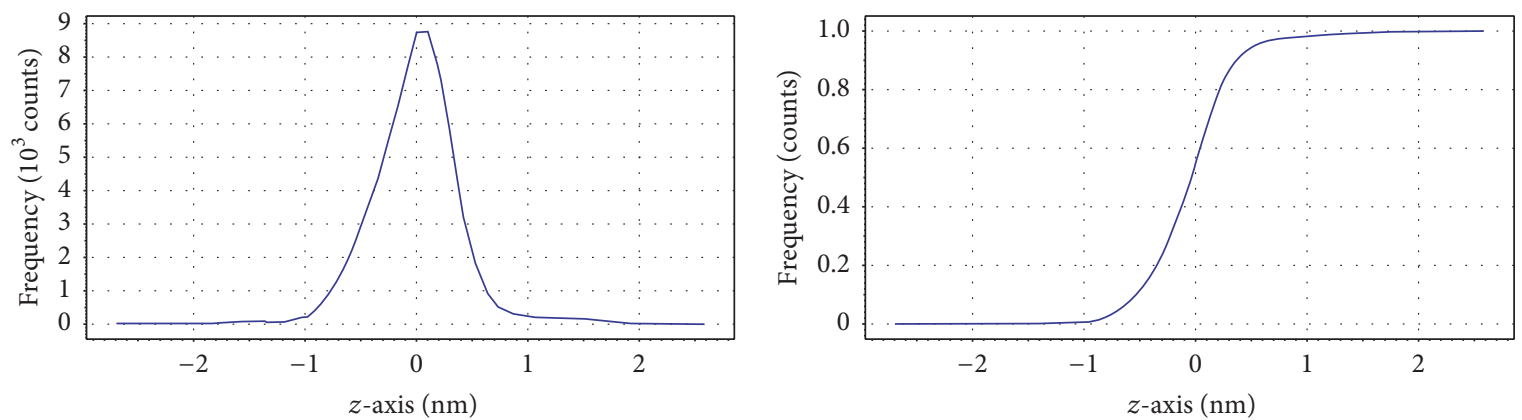

(a)
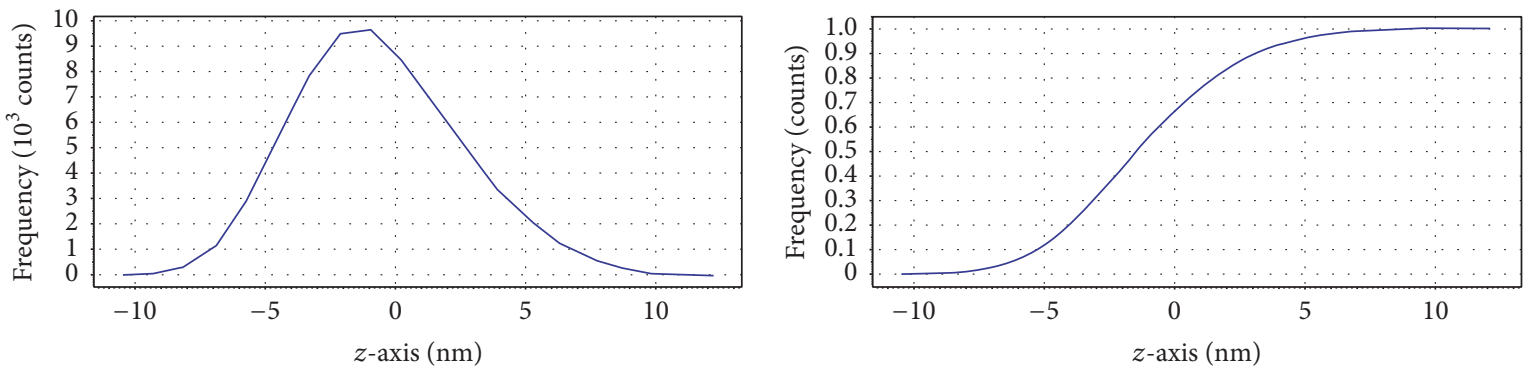

(b)
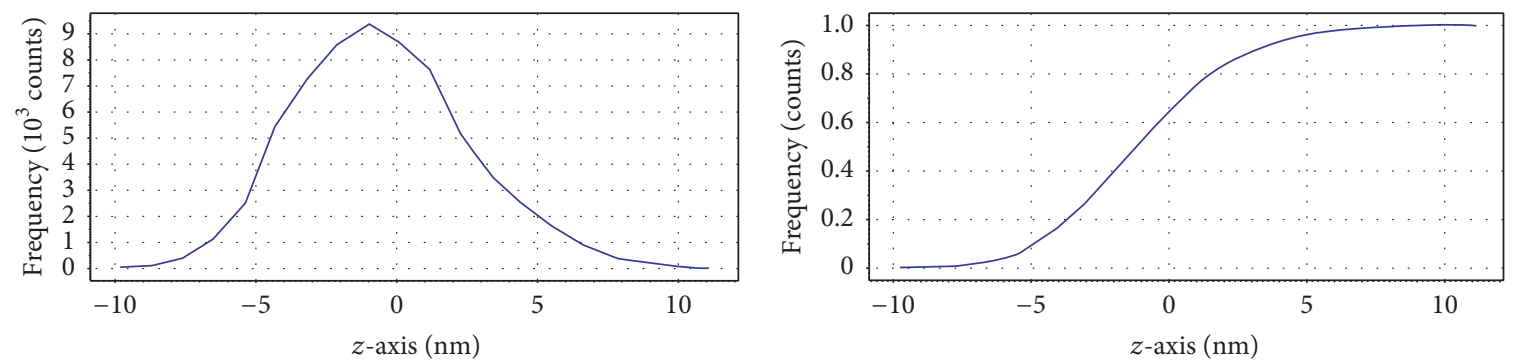

(c)
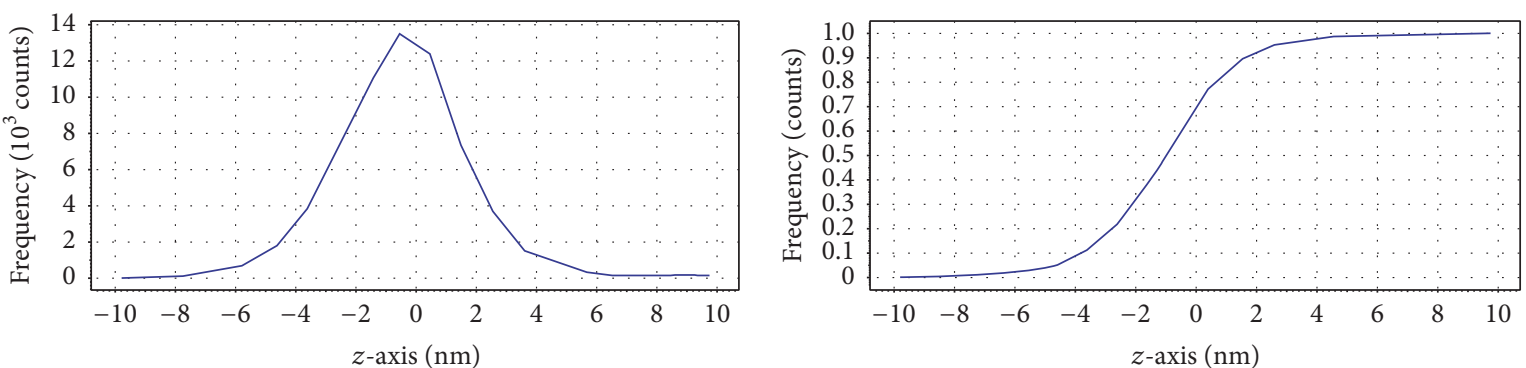

(d)
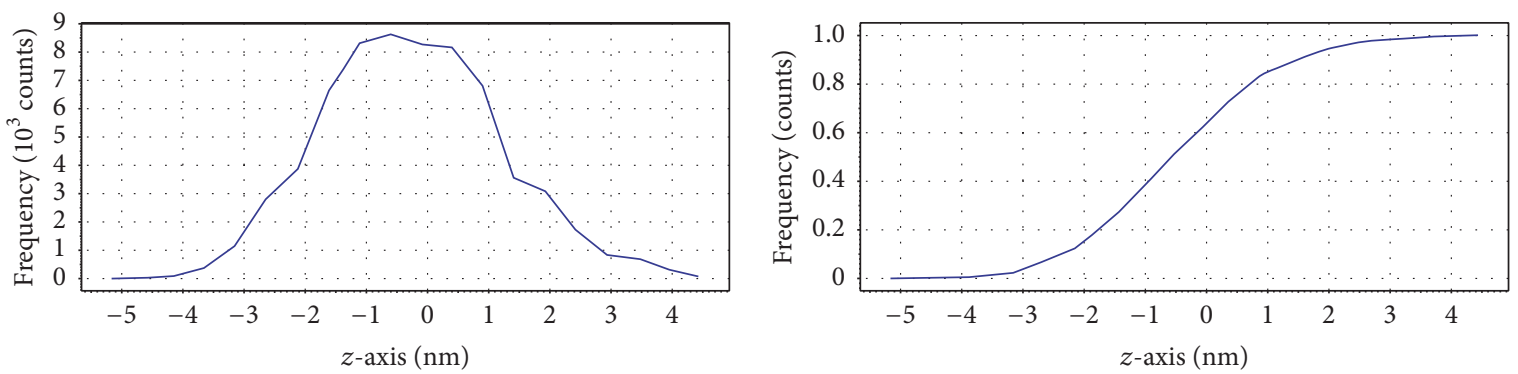

(e)

Figure 3: AFM roughness analysis with different deposition time, (a) $5 \mathrm{~min}$, (b) $20 \mathrm{~min}$, (c) $35 \mathrm{~min}$, (d) $65 \mathrm{~min}$, and (e) $85 \mathrm{~min}$. First column for histogram and the second for peak distribution. 


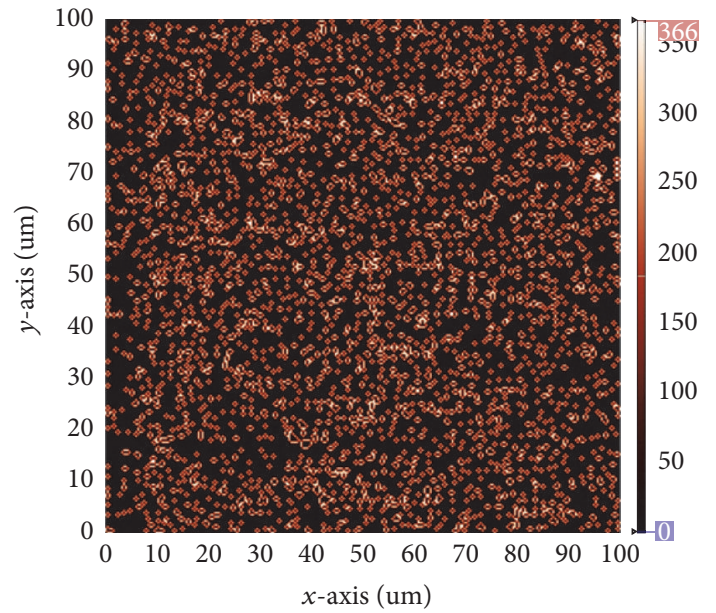

(a)

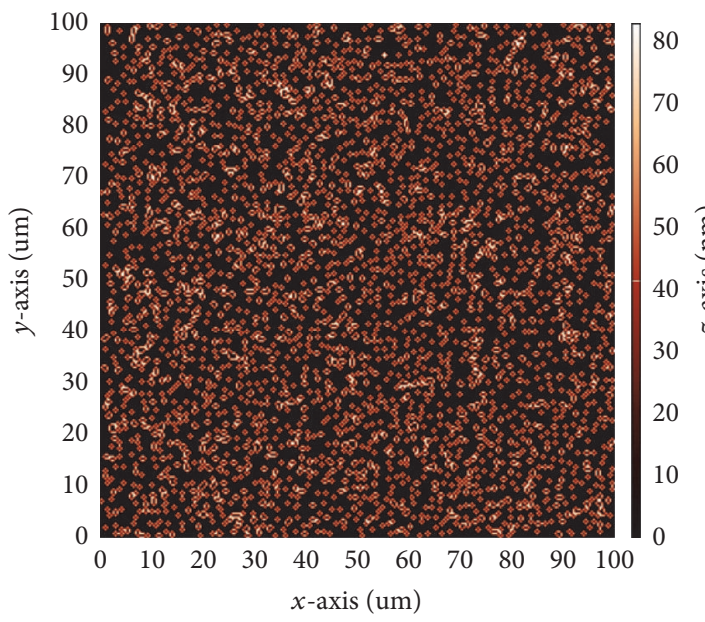

(c)

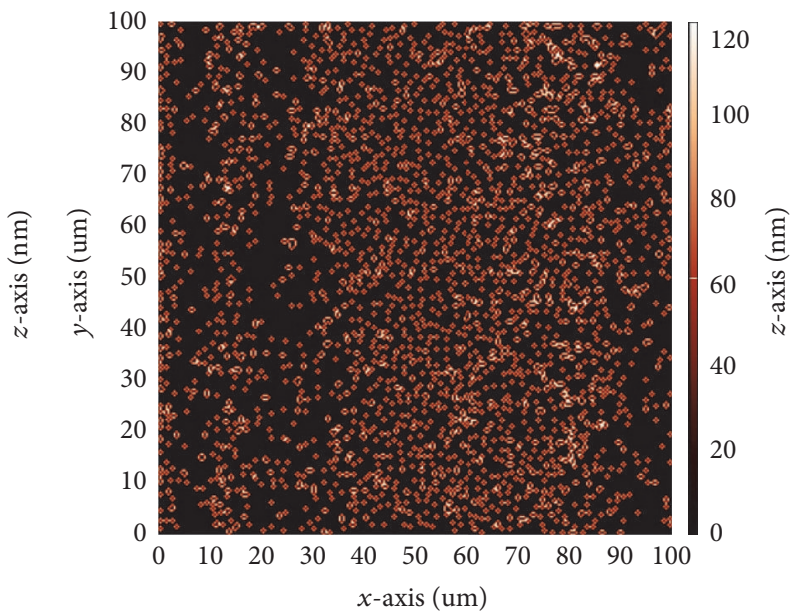

(b)

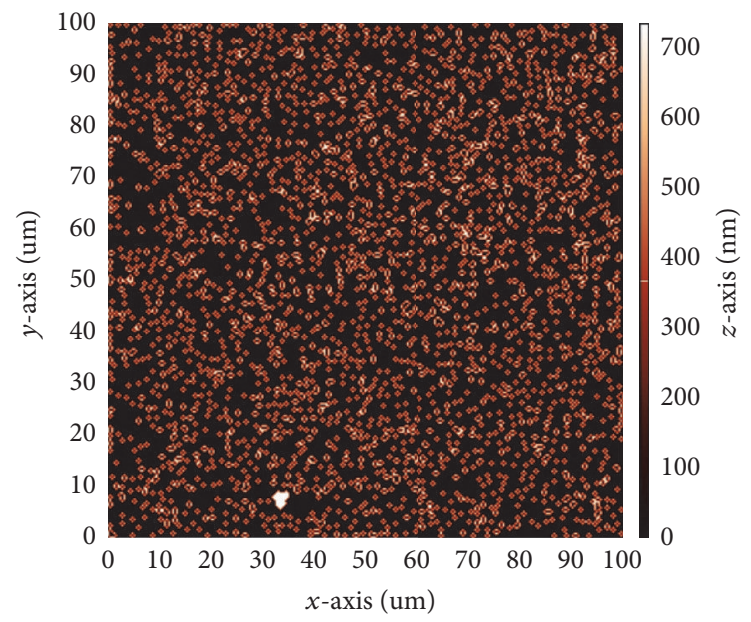

(d)

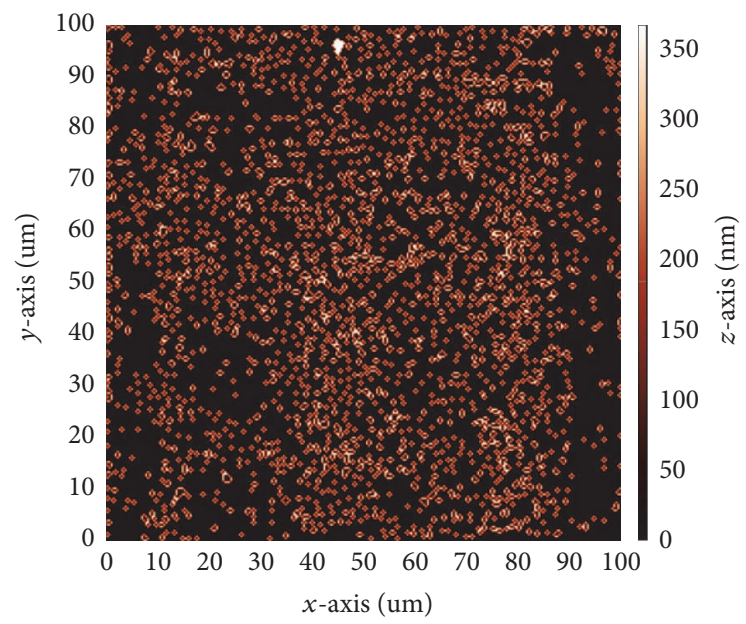

(e)

FIGURE 4: 2D image shows the grain distribution of Mo films with different deposition time, (a) $5 \mathrm{~min}$, (b) $20 \mathrm{~min}$, (c) $35 \mathrm{~min}$, (d) $65 \mathrm{~min}$, and (e) $85 \mathrm{~min}$. 

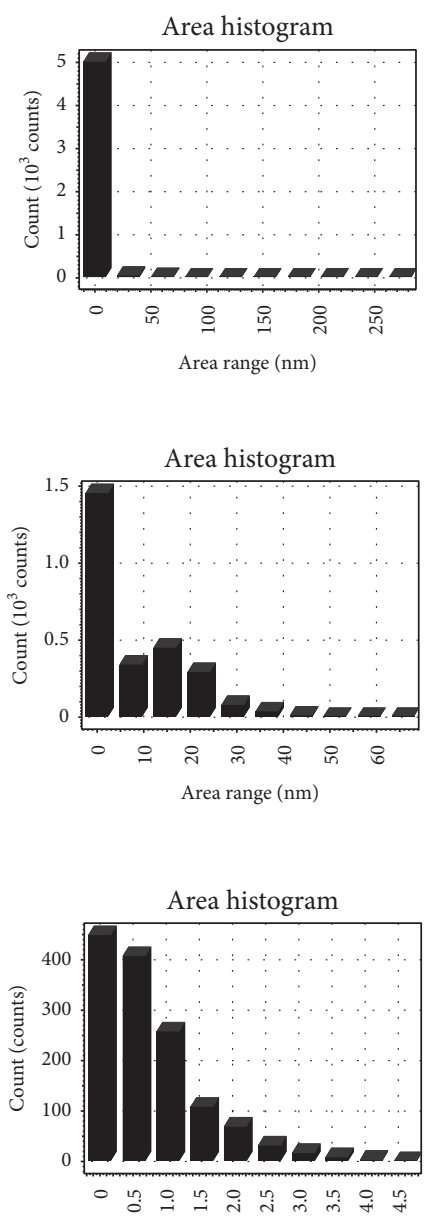

Area range $(\mathrm{nm})$
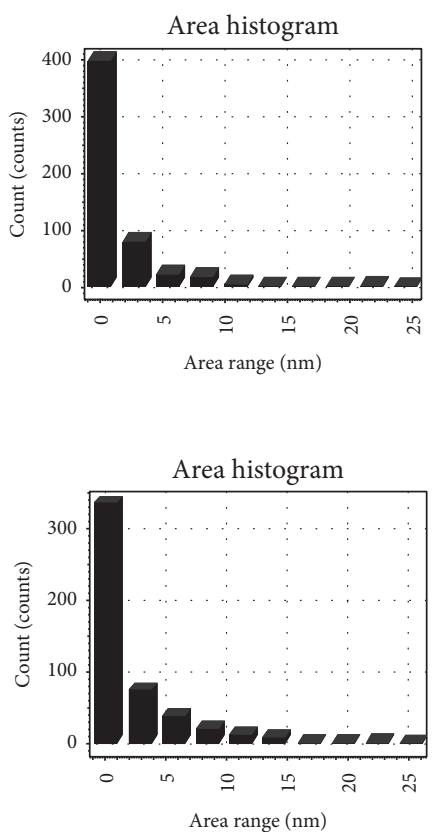
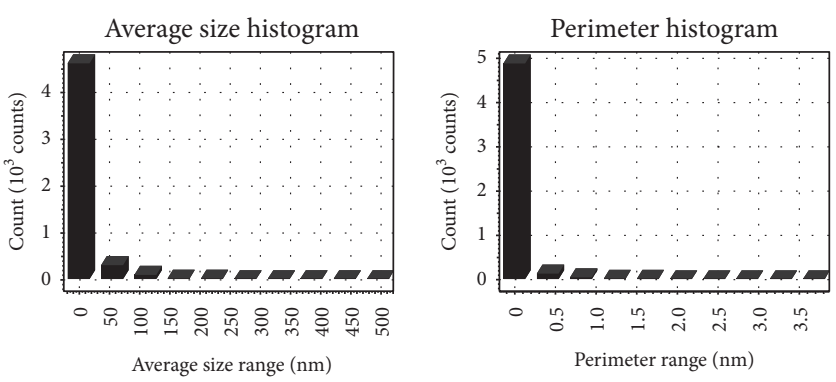

(a)
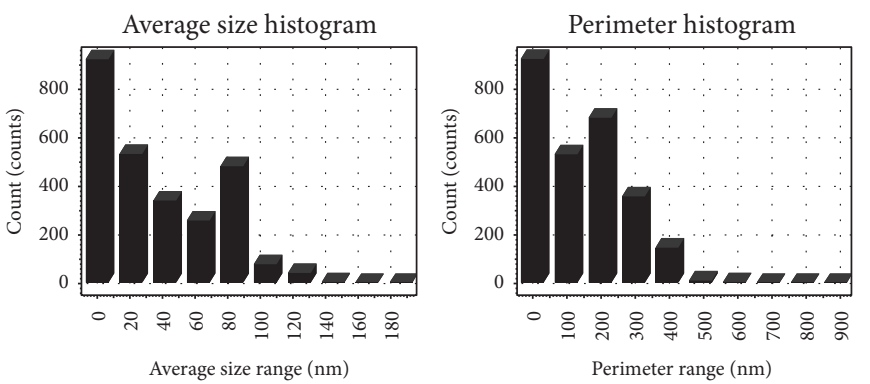

(b)
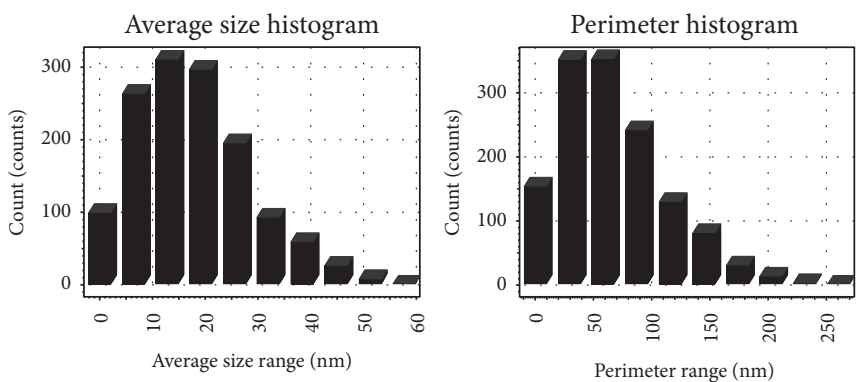

(c)
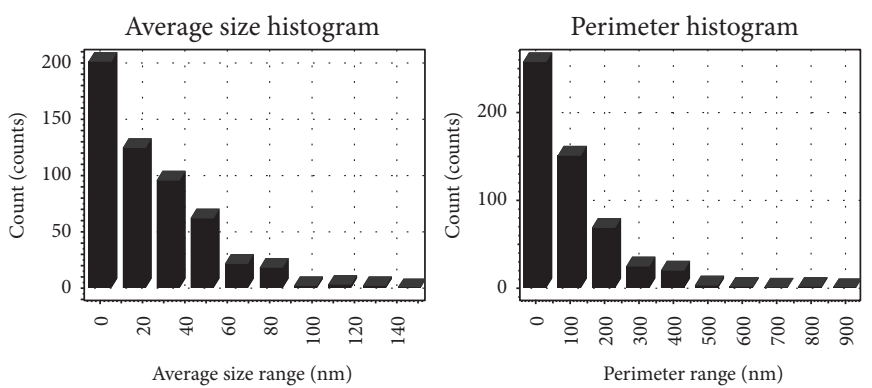

(d)
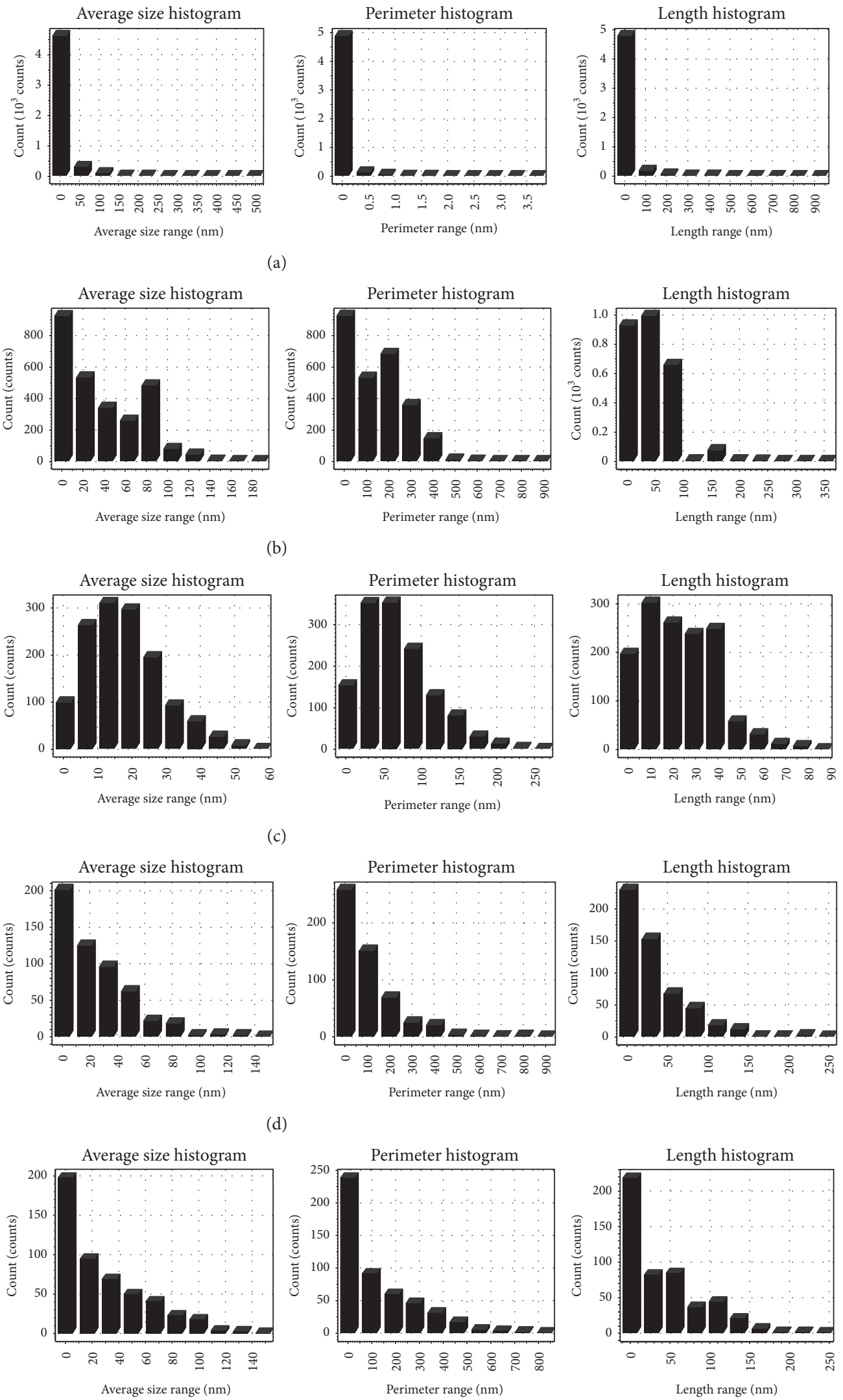

(e)

FIGURE 5: Quantitative analysis of nanostructured for Mo thin film with different deposition time, (a) 5 min, (b) 20 min, (c) 35 min, (d) 65 min, and (e) $85 \mathrm{~min}$. 
area, grain size, length, and perimeter) of Mo thin films nanostructure with different deposition time. Small grain size is preferable as it increases the films toughness.

\section{Conclusions}

In this work surface profiler and AFM have been used to characterize surface thickness, roughness, and grain analysis of Mo thin film deposited on Si substrate with different deposition time (5-85 minutes). Image analysis P9 has been used to process the data from AFM and produce the statistical information such as 2D, 3D, and histogram. Deposition rate for all samples has been calculated and it has been found to be $0.0337 \mathrm{~nm} / \mathrm{s}$ for sample with 5 -minute deposition time. The deposition rate increases for other samples to the point that it remains constant after $20 \mathrm{~min}$ at $0.22 \mathrm{~nm} / \mathrm{s}$. The result showed that the films surfaces have smooth surface texture. For all samples, the distributions are Gaussian and the peaks are dominant over the valleys. The surface roughness decreases with time. The grain analysis for all samples showed that the grain parameter values increase with respect to time and very good distribution of grain along the surface. This type of study provides more extensive understanding of the influence of time on thickness and surface morphology of the films. Other than the deposition time, similar analysis could also be made with variation of DC sputtering power, sputtering pressure, and sputtering argon flow rate. This could help in choosing suitable deposition parameters according to thickness and surface morphology requirements for any application such as fabrication of the electrode for the carbon nanotube transistor.

\section{Competing Interests}

The authors declare that they have no competing interests.

\section{Acknowledgments}

This work has been supported by Ministry of Science, Technology \& Innovation (MOSTI) under Grant (03-0114-SF0095 L00023). The authors would like to acknowledge the Center of Research and Innovation Management (CRIM) in Universiti Teknikal Malaysia Melaka and Universiti Kebangsaan Malaysia.

\section{References}

[1] R. Ghodssi and P. Lin, Eds., MEMS Materials and Processes Handbook, Springer, Berlin, Germany, 1st edition, 2011.

[2] S. Beeby, G. Ensell, M. Kraft, and N. White, MEMS Mechanical Sensors, Artech House, Boston, Mass, USA, 2004.

[3] B. Bhushan, Tribology Issues and Opportunities in MEMS: Proceedings of the NSF/AFOSR/ASME Workshop on Tribology Issues and Opportunities in MEMS held in Columbus, Ohio, USA, 9-11 November 1997, Springer, 2012.

[4] "Sandia National laboratories," 2015, http://www.sandia.gov/ $\mathrm{mstc} / \mathrm{mems} /$.

[5] B. Bhushan, Springer Handbook of Nanotechnology, Springer Science \& Business Media, Berlin, Germany, 2010.
[6] B. Bhushan, Handbook of Micro/Nano Tribology, CRC Press, 2nd edition, 1998.

[7] A. S. M. Jaya, N. A. Abdul Kadir, and M. I. Jarrah, "Modeling of TiN coating roughness using fuzzy logic approach," Science International, vol. 26, no. 4, pp. 1563-1567, 2014.

[8] A. S. Mohamad Jaya, M. I. Mohammad Jarrah, and M. R. Muhamad, "Modeling of TiN coating grain size using RSM approach," Applied Mechanics and Materials, vol. 754-755, pp. 738-742, 2015.

[9] M. I. Jarrah, A. S. M. Jaya, M. R. Muhamad, M. N. Abd Rahman, and A. S. H. Basari, "Modeling and optimization of physical vapour deposition coating process parameters for TiN grain size using combined genetic algorithms with response surface methodology," Journal of Theoretical and Applied Information Technology, vol. 77, no. 2, pp. 235-253, 2015.

[10] D. A. H. Hanaor, G. Triani, and C. C. Sorrell, "Morphology and photocatalytic activity of highly oriented mixed phase titanium dioxide thin films," Surface and Coatings Technology, vol. 205, no. 12, pp. 3658-3664, 2011.

[11] T. Mehmood, A. Kaynak, X. J. Dai et al., "Study of oxygen plasma pre-treatment of polyester fabric for improved polypyrrole adhesion," Materials Chemistry and Physics, vol. 143, no. 2, pp. 668-675, 2014.

[12] A. Duk, M. Schmidbauer, and J. Schwarzkopf, "Anisotropic onedimensional domain pattern in $\mathrm{NaNbO}_{3}$ epitaxial thin films grown on (110) $\mathrm{TbScO}_{3}$," Applied Physics Letters, vol. 102, no. 9, Article ID 091903, 2013.

[13] K. Khojier, M. R. Mehr, and H. Savaloni, "Annealing temperature effect on the mechanical and tribological properties of molybdenum nitride thin films," Journal of Nanostructure in Chemistry, vol. 3, no. 1, article no. 5, 2013.

[14] R. F. Kwasnick, G. E. Possin, D. E. T. L. Holden, and R. J. Saia, "Thin film transistor stucture with improved source/drain contacts," 1996.

[15] M. A. Mohamed, M. A. Azam, E. Shikoh, and A. Fujiwara, "Fabrication and characterization of carbon nanotube fieldeffect transistors using ferromagnetic electrodes with different coercivities," Japanese Journal of Applied Physics, vol. 49, no. 2, Article ID 02BD08, 2010.

[16] R. Latif, E. Mastropaolo, A. Bunting et al., "Microelectromechanical systems for biomimetical applications," Journal of Vacuum Science and Technology B:Nanotechnology and Microelectronics, vol. 28, no. 6, 2010.

[17] S. Lee, J. Y. Kim, T.-W. Lee et al., "Fabrication of high-quality single-crystal cu thin films using radio-frequency sputtering," Scientific Reports, vol. 4, article 6230, 2014.

[18] J. H. Scofield, A. Duda, D. Albin, B. L. Ballard, and P. K. Predecki, "Sputtered molybdenum bilayer back contact for copper indium diselenide-based polycrystalline thin-film solar cells," Thin Solid Films, vol. 260, no. 1, pp. 26-31, 1995.

[19] G. Gordillo, M. Grizález, and L. C. Hernandez, "Structural and electrical properties of DC sputtered molybdenum films," Solar Energy Materials and Solar Cells, vol. 51, no. 3-4, pp. 327-337, 1998.

[20] F. Martin, P. Muralt, and M.-A. Dubois, "Process optimization for the sputter deposition of molybdenum thin films as electrode for AlN thin films," Journal of Vacuum Science and Technology A: Vacuum, Surfaces and Films, vol. 24, no. 4, pp. 946-952, 2006.

[21] Z.-H. Li, E.-S. Cho, and S. J. Kwon, "Molybdenum thin film deposited by in-line DC magnetron sputtering as a back contact 
for $\mathrm{Cu}(\mathrm{In}, \mathrm{Ga}) \mathrm{Se} 2$ solar cells," Applied Surface Science, vol. 257, no. 22, pp. 9682-9688, 2011.

[22] T. Lyubenova, D. Fraga, A. Rey, R. Marti, S. Kozhukarov, and J. Carda, "Electrical and Morphological study of Mo thin films for solar cell applications," Rousse University "Angel Kanchev", vol. 52, pp. 11-15, 2013.

[23] N. Kumari, A. K. Singh, and P. K. Barhai, "Study of properties of AlN thin films deposited by reactive magnetron sputtering," International Journal of Thin Films Science and Technology, vol. 3, no. 2, pp. 43-49, 2014.

[24] K. R. Nagabhushana, B. N. Lakshminarasappa, K. Narasimha Rao, F. Singh, and I. Sulania, "AFM and photoluminescence studies of swift heavy ion induced nanostructured aluminum oxide thin films," Nuclear Instruments and Methods in Physics Research, Section B: Beam Interactions with Materials and Atoms, vol. 266, no. 7, pp. 1049-1054, 2008.

[25] D. Nesheva, A. Petrova, S. Stavrev, Z. Levi, and Z. Aneva, "Thin film semiconductor nanomaterials and nanostructures prepared by physical vapour deposition: an atomic force microscopy study," Journal of Physics and Chemistry of Solids, vol. 68, no. 5-6, pp. 675-680, 2007.

[26] A. Heredia, C. C. Bui, U. Suter, P. Young, and T. E. Schäffer, "AFM combines functional and morphological analysis of peripheral myelinated and demyelinated nerve fibers," NeuroImage, vol. 37, no. 4, pp. 1218-1226, 2007.

[27] D. Marchetto, A. Rota, L. Calabri, G. C. Gazzadi, C. Menozzi, and S. Valeri, "AFM investigation of tribological properties of nano-patterned silicon surface," Wear, vol. 265, no. 5-6, pp. 577$582,2008$.

[28] N. Jalili and K. Laxminarayana, "A review of atomic force microscopy imaging systems: application to molecular metrology and biological sciences," Mechatronics, vol. 14, no. 8, pp. 907-945, 2004.

[29] M. Kwoka, L. Ottaviano, and J. Szuber, "AFM study of the surface morphology of L-CVD SnO2 thin films," Thin Solid Films, vol. 515, no. 23, pp. 8328-8331, 2007.

[30] Y. Strausser, Characterization in Silicon Processing, Elsevier, 2013.

[31] B. Bhushan, "Surface Roughness Analysis and Measurement Techniques," in Modern Tribology Handbook, CRC Press, 2000.

[32] B. Rajesh Kumar and T. Subba Rao, "AFM studies on surface morphology, topography and texture of nanostructured zinc aluminum oxide thin films," Digest Journal of Nanomaterials and Biostructures, vol. 7, no. 4, pp. 1881-1889, 2012.

[33] D. Raoufi, A. Kiasatpour, H. R. Fallah, and A. S. H. Rozatian, "Surface characterization and microstructure of ITO thin films at different annealing temperatures," Applied Surface Science, vol. 253, no. 23, pp. 9085-9090, 2007.

[34] H. Ward, Profile Characterization. Rough Surfaces, Edited by T. R. Thomas, Longman, London, UK, 1982. 

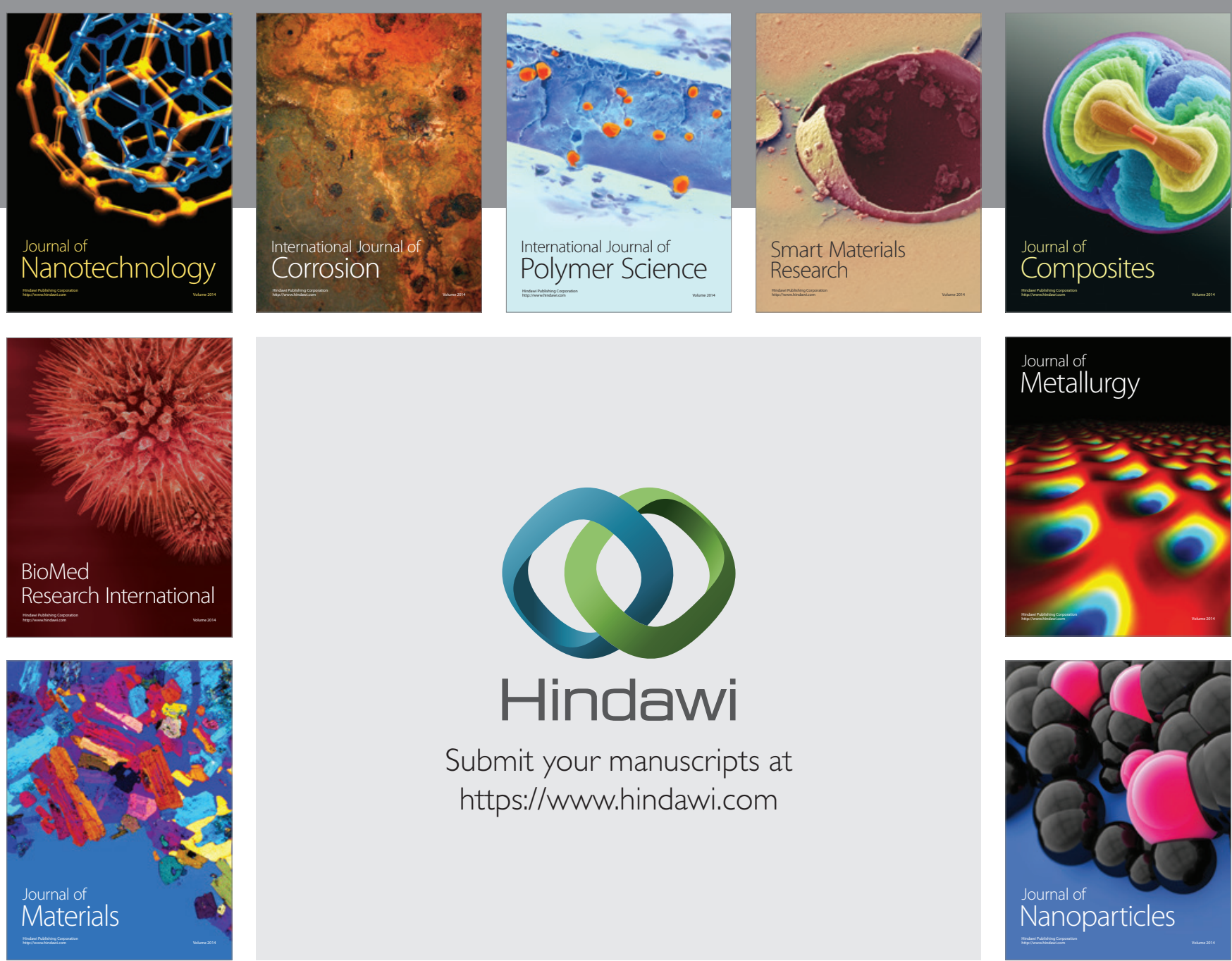

\section{Hindawi}

Submit your manuscripts at

https://www.hindawi.com

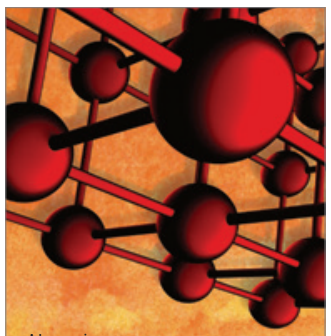

Materials Science and Engineering
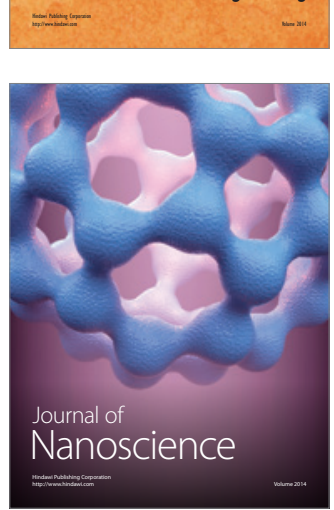
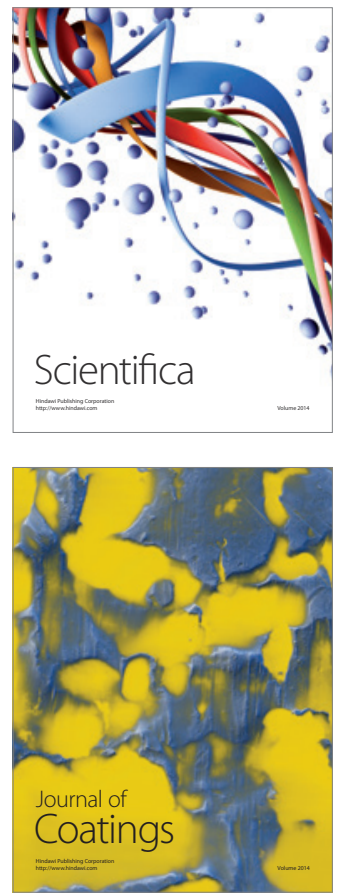
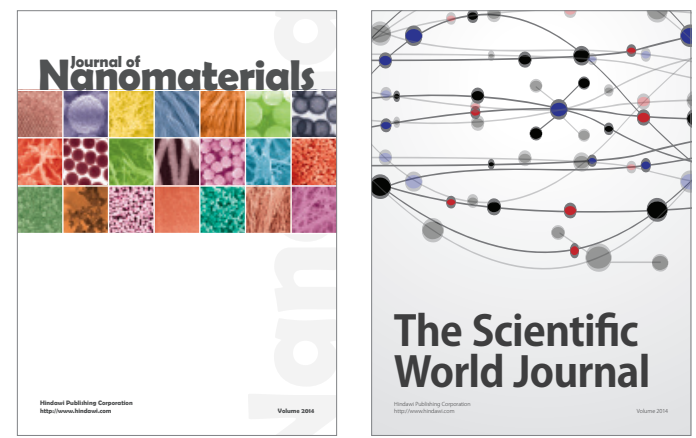

The Scientific World Journal
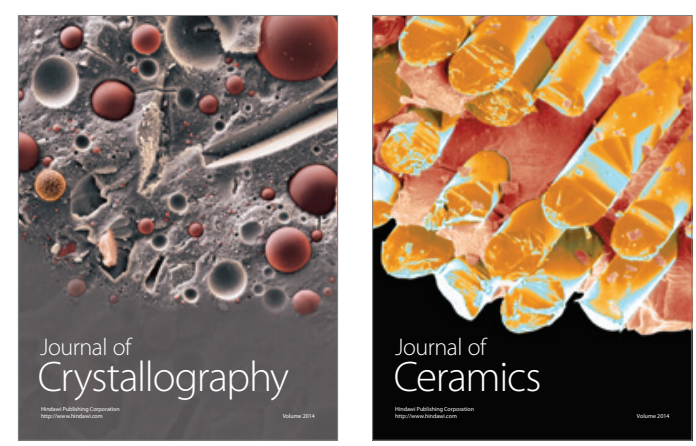
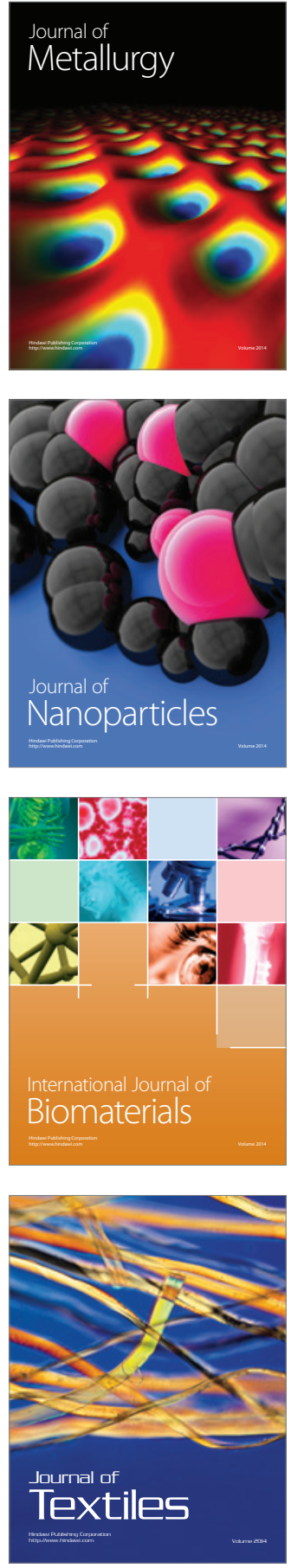